\title{
Trade Liberalization, Macroeconomic Adjustment, and Welfare: Unifying Trade and Macro Models
}

Ehsan Choudhri, Hamid Faruqee, and Stephen Tokarick 



\title{
IMF Working Paper
}

\author{
Research Department
}
Trade Liberalization, Macroeconomic Adjustment, and Welfare: Unifying Trade and Macro Models

\section{Prepared by Ehsan Choudhri, Hamid Faruqee, and Stephen Tokarick ${ }^{1}$}

\author{
Authorized for distribution by Shang-Jin Wei
}

December 2006

\begin{abstract}
This Working Paper should not be reported as representing the views of the IMF. The views expressed in this Working Paper are those of the author(s) and do not necessarily represent those of the IMF or IMF policy. Working Papers describe research in progress by the author(s) and are published to elicit comments and to further debate.

Trade liberalization leads to long-run gains, but it can also involve costly short-run macroeconomic adjustment. The paper explores the relative importance of these effects within a dynamic general equilibrium model that captures key elements of both international trade and macroeconomic models. The welfare effect of trade liberalization is decomposed into a steady-state efficiency gain and a transitional loss associated with wage-price stickiness. Our estimates show that the transitional loss is small relative to the steady-state gain, and tends to be lower under flexible as compared to fixed exchange rates. We also show that the loss can be reduced further by a flexible price-level targeting policy rule.
\end{abstract}

JEL Classification Numbers: F12, F13, F41

Keywords: Trade liberalization, macroeconomic adjustment, welfare cost of tariffs Author(s) E-mail addresses: Ehsan_choudhri@carleton.edu; hfaruqee@imf.org; stokarick@imf.org

\footnotetext{
${ }^{1}$ Ehsan Choudhri, Chancellor's Professor of Economics, Carleton University, Ottawa, Ontario, Canada; Hamid Faruqee and Stephen Tokarick, Research Department, International Monetary Fund. We would like to thank Ayhan Kose and participants of a conference at the IMF for helpful comments.
} 


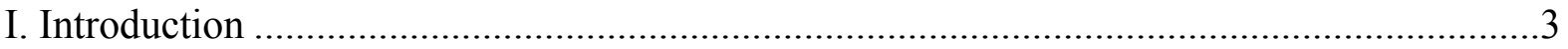

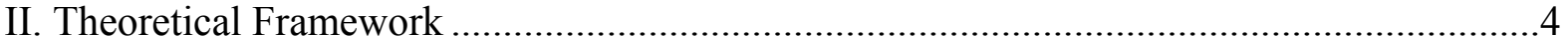

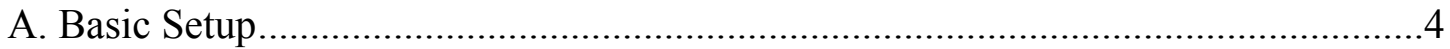

B. Consumption and Production .............................................................................

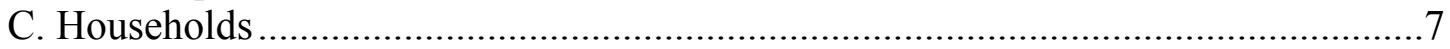

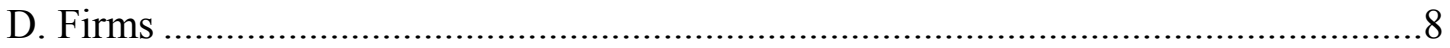

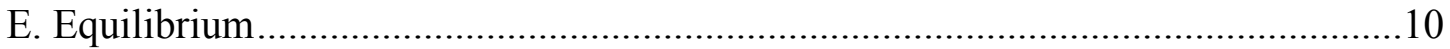

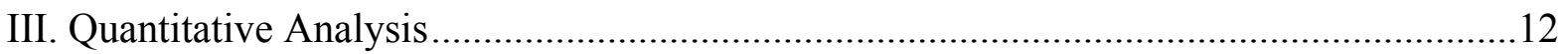

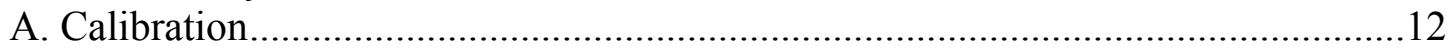

B. Macroeconomic Adjustment ...................................................................... 14

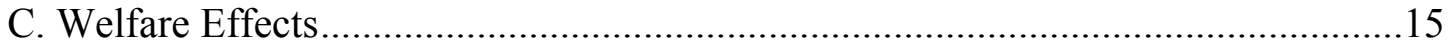

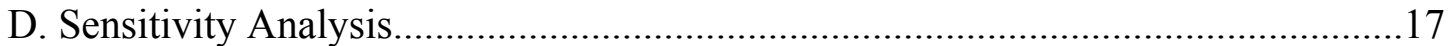

E. No International Capital Mobility ........................................................... 18

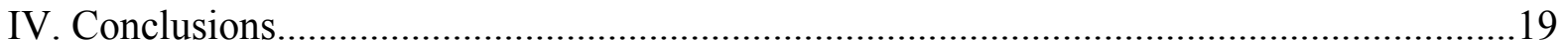

References.................................................................. 20

Tables

1. Baseline Model: Parameter Values and Normalizations..............................22

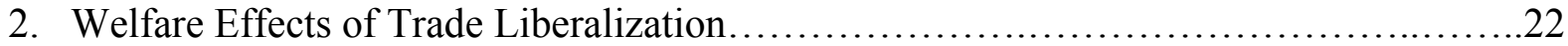

Figures

1. Dynamic Response of Real Variables to Trade Liberalization.........................23

2. Dynamic Response of Nominal Variables to Trade Liberalization......................24

3. Transitional Losses under Different Values of Delta................................25

4. Distribution of Loss-Ratio Estimates under Fixed and Flexible Exchange Rates.........25

5. Transitional Losses under Different Values of Omega: Fixed Versus Flexible

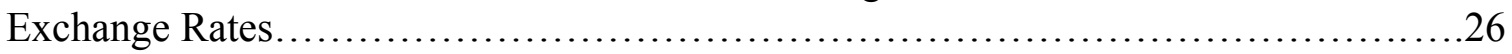




\section{INTRODUCTION}

There are two distinct strands in the extensive literature on the economic effects of trade policy. One strand is mainly concerned with the long-run effect of trade policy on economic welfare and employs international trade models with flexible prices to determine this effect. In this analysis, trade liberalization generally enhances welfare by improving economic efficiency. ${ }^{2}$ The other strand uses macroeconomic models with nominal rigidities to examine the short-run consequences of trade policy on variables such as output, employment, and the current account. The response of macroeconomic variables to trade liberalization in these models depends, among other things, on monetary policy. For example, under fixed exchange rates, tariff cuts lower the relative price of foreign goods and (in the presence of sticky prices) typically cause a temporary contraction of output and employment as well as a deficit in the current account. ${ }^{3}$ These effects can be altered by home currency depreciation under flexible exchange rates. ${ }^{4}$ Macroeconomic adjustment to trade liberalization could potentially involve substantial costs. There is little work, however, which has integrated the two strands to compare - under different monetary policy regimes - the short-run adjustment costs of trade liberalization with the long-run efficiency benefits.

Early macroeconomic models did not have strong microeconomic foundations and thus did not examine the welfare implications of macroeconomic adjustment to trade policy. ${ }^{5}$ The optimizing framework of the "new open economy macroeconomic models," however, makes it possible to evaluate the welfare effect of adjustment. These models, however, differ from international trade models in important respects. A key difference is that while international trade models allow wages and prices to be flexible and often assume competitive conditions, macroeconomic models introduce wage-price inertia and assume imperfect competition to motivate this behavior. Another important difference arises from the assumption regarding the number of sectors producing traded goods: there is typically only one traded-goods sector in macroeconomic models, but at least two traded-goods sectors in international trade models. These differences make it difficult to compare the welfare results derived from the two types of models. This paper develops a simple hybrid model that captures the key elements of both approaches and provides a unifying framework to examine the welfare consequences of both the short- and long-run effects of changes in trade policy.

Macroeconomic adjustment to trade liberalization is identified in the model with transitional dynamics arising from wage-price inertia. The welfare effect of removing trade

\footnotetext{
${ }^{2}$ Adverse terms-of-trade effects or market failure can qualify this result.

${ }^{3}$ See Chacholiades (1978) and Dornbusch (1980) for a discussion of the macroeconomic effects of a tariff (which are opposite to those of trade liberalization) under fixed exchange rates.

${ }^{4}$ For an early analysis of the macroeconomic effects of a tariff under flexible exchange rates, see Mundell (1961). Also see Boyer (1977) and Krugman (1982) for further analysis of these effects.

${ }^{5}$ There is literature going back to Razin and Svensson (1983), which uses an optimizing framework without nominal rigidities to analyze the effect of a tariff on the current account.
} 
restrictions can be decomposed into a transitional and a steady-state effect. The steady-state effect captures efficiency gains associated with long-run resource allocation. Since sticky wages and prices slow down the adjustment towards a more efficient allocation of resources, the transitional effect involves a loss (i.e., the total welfare effect is smaller than the steadystate effect). This loss represents the cost of macroeconomic adjustment to a reduction of trade barriers.

One issue that has not been adequately examined is whether macroeconomic adjustment costs are sufficiently large to significantly offset long-run benefits of trade liberalization. To explore this question, the paper estimates transitional and steady-state welfare effects of tariff reduction for a hypothetical small country. We focus on the case of a developing economy that is financially integrated with the rest of the world. ${ }^{6}$ One interesting result of the paper's quantitative analysis is that the macroeconomic costs of a tariff reduction turn out to be small in relation to long-term efficiency gains for a wide range of parameter values.

The paper also explores how monetary policy affects the macroeconomic costs of liberalizing trade. The paper finds that flexible exchange rates (with a constant price level) involve a lower loss than fixed exchange rates under nearly all plausible parameterizations. In addition to fixed and flexible exchange rate regimes, the paper considers a flexible pricelevel targeting rule with the interest rate as an instrument. This rule performs better than both regimes, in the sense that it leads to a smaller transitional loss. In fact, a sufficiently weak interest rate response to the price level can come close to duplicating the flexible wage-price equilibrium (that eliminates transitional dynamics) and entails little or no macroeconomic adjustment cost. An extensive sensitivity analysis is undertaken to investigate the robustness of our results. Our basic result that the transitional loss is relatively small holds for a wide range of parameter values and policy regimes. However, we do find that for a financially closed economy (that has to keep its current account in balance), the fixed exchange rate regime leads to costly macroeconomic adjustment and a significant reduction in the gains from trade liberalization.

The basic model is developed in Section II. Section III parameterizes the model and uses it to estimate macroeconomic and welfare effects of trade liberalization. Section IV concludes the paper.

\section{THEORETICAL FRAMEWORK}

\section{A. Basic Setup}

This section develops a basic dynamic general equilibrium model to examine the short- and long-run effects of trade policy changes. There are two countries, a small home

\footnotetext{
${ }^{6}$ The term "developing" is used broadly to refer to countries at low and medium income levels. In this group, countries with relatively high exposure to international capital markets tend to be in the middle-income category and are generally classified as emerging economies (e.g., see Obstfeld, 2004).
} 
country and a large foreign country. Two goods, $M$ and $X$, are produced in the two countries. The production of each good requires labor and capital specific to each sector. Capital endowments are fixed (as in trade models), but labor supply is variable (as in macroeconomic models).

To introduce nominal rigidities in the model, it is assumed that both goods and labor markets are characterized by monopolistic competition, and changes in wages and prices are subject to adjustment costs. There is interindustry as well as intraindustry trade. The home country is a net importer of good $M$ and a net exporter of good $X$. Trade restrictions take the form of import tariffs.

Households trade a short-term foreign bond denominated in foreign currency to borrow or lend internationally. International borrowing or lending is unrestricted but subject to a transaction cost that increases in foreign debt. There are no stochastic shocks in the model and the inflation rate equals zero in steady state.

\section{B. Consumption and Production}

The household's consumption basket is given by

$$
C_{t}=\left[\chi_{M}^{1 / \eta} C_{M, t}^{(\eta-1) / \eta}+\chi_{X}^{1 / \eta} C_{X, t}^{(\eta-1) / \eta}\right]^{\eta /(\eta-1)},
$$

where $C_{M, t}$ and $C_{X, t}$ are consumption indexes for goods $M$ and $X, \eta$ is the elasticity of substitution between the two goods, and $\chi_{M}+\chi_{X}=1$. The consumption index for each sector is defined as

$$
C_{T, t}=\left[\chi_{T H}^{1 / \theta_{T}} C_{T H, t}^{\left(\theta_{T}-1\right) / \theta_{T}}+\chi_{T F}^{1 / \theta_{T}} C_{T F, t}^{\left(\theta_{T}-1\right) / \theta_{T}}\right]^{\theta_{T} /\left(\theta_{T}-1\right)}, T=M, X
$$

where, for sector $T(=M, X), C_{T H, t}$ and $C_{T F, t}$ are consumption bundles of home and foreign varieties, respectively, $\theta_{T}$ represents the elasticity of substitution between the home and foreign bundles, and $\chi_{T H}+\chi_{T F}=1$.

For each good, there is a continuum of home and foreign varieties in the unit interval. Consumption aggregates of home and foreign varieties, indexed by $h, f \in[0,1]$, for the two goods are

$$
C_{T H, t}=\left[\int_{0}^{1} C_{T H, t}(h)^{\left(\varepsilon_{T}-1\right) / \varepsilon_{T}} d h\right]^{\varepsilon_{T} /\left(\varepsilon_{T}-1\right)}, C_{T F, t}=\left[\int_{0}^{1} C_{T F, t}(f)^{\left(\varepsilon_{T}-1\right) / \varepsilon_{T}} d f\right]^{\varepsilon_{T} /\left(\varepsilon_{T}-1\right)}, T=M, X,
$$

where, for simplicity, the elasticity of substitution among varieties, $\varepsilon_{T}$, is assumed to be the same for home and foreign bundles of each good. 
Optimal allocation of consumption expenditures between the two goods, between the home and foreign bundles of each good, and among different varieties of each bundle leads to the following demand functions:

$$
\begin{gathered}
C_{M, t}=\chi_{M} C_{t}\left(P_{M, t} / P_{t}\right)^{-\eta}, \quad C_{X, t}=\chi_{X} C_{t}\left(P_{X, t} / P_{t}\right)^{-\eta}, \\
C_{T H, t}=\chi_{T H} C_{T, t}\left(P_{T H, t} / P_{T, t}\right)^{-\theta_{T}}, C_{T F, t}=\chi_{T F} C_{T, t}\left(P_{T F, t} / P_{T, t}\right)^{-\theta_{T}}, T=M, X, \\
C_{T H, t}(h)=C_{T H, t}\left(P_{T H, t}(h) / P_{T H, t}\right)^{-\varepsilon_{T}}, C_{T F, t}(f)=C_{T F, t}\left(P_{T F, t}(f) / P_{T F, t}\right)^{-\varepsilon_{T}}, T=M, X,
\end{gathered}
$$

where $P_{T H, t}(h)$ and $P_{T F, t}(f)$ are the prices of varieties of home and foreign goods; $P_{T H, t}$ and $P_{T F, t}$ are price indexes that minimize the unit cost of home and foreign bundles defined in (3), and $P_{t}$ and $P_{T, t}$ are the cost-minimizing price indexes for the aggregate basket (1) and the consumption index (2). These price indexes are given by

$$
\begin{gathered}
P_{t}=\left[\chi_{M} P_{M . t}^{1-\eta}+\chi_{X} P_{X, t}^{1-\eta}\right]^{1 /(1-\eta)}, \\
P_{T, t}=\left[\chi_{T H} P_{T H, t}^{1-\theta_{T}}+\chi_{T F} P_{T F, t}^{1-\theta_{T}}\right]^{1 /\left(1-\theta_{T}\right)}, T=M, X, \\
P_{T H, t}=\left[\int_{0}^{1} P_{T H, t}(h)^{1-\varepsilon_{T}} d h\right]^{1 /\left(1-\varepsilon_{T}\right)}, P_{T F, t}=\left[\int_{0}^{1} P_{T F, t}(f)^{1-\varepsilon_{T}} d f\right]^{1 /\left(1-\varepsilon_{T}\right)}, T=M, X .
\end{gathered}
$$

Optimal allocation of consumption expenditures abroad yields similar expressions for foreign demand functions and price indexes. Letting an asterisk denote foreign variables and parameters, the foreign demand for home bundles and varieties can be expressed as:

$$
C_{T H, t}^{*}=\chi_{T H}^{*} C_{T, t}^{*}\left(P_{T H, t}^{*} / P_{T, t}^{*}\right)^{-\theta_{T}^{*}}, \quad C_{T H, t}^{*}(h)=C_{T H, t}^{*}\left(P_{T H, t}^{*}(h) / P_{T H, t}^{*}\right)^{-\varepsilon_{T}}, T=M, X,
$$

where the substitution elasticity between the home and foreign bundles abroad is allowed to be different than that at home.

For each good, the production technology for a firm is given by the following CES production function:

$$
Y_{T, t}=\left[\alpha_{T}^{1 / \sigma} L_{T, t}^{(\sigma-1) / \sigma}+\left(1-\alpha_{T}\right)^{1 / \sigma} K_{T, t}^{(\sigma-1) / \sigma}\right]^{\sigma /(\sigma-1)}, T=M, X
$$

where $Y_{M, t}, L_{M, t}$ and $K_{M, t}$ represent, respectively, output, a bundle of labor inputs, and a specific capital input for good $M ; Y_{X, t}, L_{X, t}$ and $K_{X, t}$ are the corresponding variables for good $X$; and $\sigma$ is the elasticity of substitution between labor and capital for both goods. The optimal choice of inputs implies the following demand functions for labor and capital:

$$
L_{T, t}=\alpha_{T} Y_{T, t}\left(W_{t} / M C_{T, t}\right)^{-\sigma}, K_{T, t}=\left(1-\alpha_{T}\right) Y_{T, t}\left(R R_{T, t} / M C_{T, t}\right)^{-\sigma}, T=M, X
$$


where $W_{t}$ is the wage index (defined below); $R R_{M, t}$ and $R R_{X, t}$ are the rental rates for capital inputs specific to goods $M$ and $X$; and $M C_{M, t}$ and $M C_{X . t}$ denote the marginal costs of producing both goods. For each good, the marginal cost equals the minimum unit cost and can be derived from (11) as

$$
M C_{T, t}=\left[\alpha_{T} W_{t}^{1-\sigma}+\left(1-\alpha_{T}\right) R R_{T, t}^{1-\sigma}\right]^{1 /(1-\sigma)}, T=M, X
$$

The labor input bundles are aggregates of differentiated services supplied by a continuum of households in the unit interval. The aggregate bundle of labor services, indexed by $l \in[0,1]$, used in the production of each good is defined as

$$
L_{M, t}=\left[\int_{0}^{1} L_{M, t}(l)^{\left(\varepsilon_{L}-1\right) / \varepsilon_{L}} d l\right]^{\varepsilon_{L} /\left(\varepsilon_{L}-1\right)}, \quad L_{X, t}=\left[\int_{0}^{1} L_{X, t}(l)^{\left(\varepsilon_{L}-1\right) / \varepsilon_{L}} d l\right]^{\varepsilon_{L} /\left(\varepsilon_{L}-1\right)},
$$

where $\varepsilon_{L}$ is the substitution elasticity for labor services. The optimal allocation of the aggregate labor input among different services in the two sectors gives the total demand for each household's service as

$$
L_{t}(l)=L_{M, t}\left(W_{t}(l) / W_{t}\right)^{-\varepsilon_{L}}+L_{X, t}\left(W_{t}(l) / W_{t}\right)^{-\varepsilon_{L}},
$$

where $W_{t}(l)$ represents the household's wage rate and $W_{t}$ is the following wage index (which minimizes the cost of the labor input bundle):

$$
W_{t}=\left[\int_{0}^{1} W_{t}(l)^{1-\varepsilon_{L}} d l\right]^{1 /\left(1-\varepsilon_{L}\right)}
$$

\section{Households}

The utility of an infinitely-lived household is given by

$$
U_{t}(l)=\sum_{s=t}^{\infty} \beta^{s-t} u\left[C_{s}(l), L_{s}(l)\right]
$$

where $C_{s}(l)$ is the household's aggregate consumption. The single-period utility is assumed to be

$$
u_{s}(.)=\left(\frac{C_{s}^{1-\rho}(l)}{1-\rho}-\frac{\psi L_{s}^{1+\mu}(l)}{1+\mu}\right)
$$

Households hold one-period domestic and foreign bonds. Domestic bonds are denominated in home currency while foreign bonds are denominated in foreign currency. Only foreign bonds are used for international borrowing or lending and their holding is subject to a transaction cost. Wage changes involve adjustment costs.

The household budget constraint is given by 


$$
\begin{aligned}
& B_{t+1}(l)+S_{t} B_{t+1}^{*}(l)=\left(1+R_{t-1}\right) B_{t}(l)+S_{t}\left(1+R_{t-1}^{*}\right)\left(1-T C_{t-1}\right) B_{t}^{*}(l) \\
& +W_{t}(l) L_{t}(l)\left(1-A C_{W, t}(l)\right)+P F_{t}(l)+R E_{t}(l)+T R_{t}(l)-P_{t} C_{t}(l),
\end{aligned}
$$

where $B_{t}(l)$ and $B_{t}^{*}(l)$ are home and foreign bonds held by households at the beginning of period $t ; S_{t}$ is the exchange rate; $R_{t-1}$ and $R_{t-1}^{*}$ are the home and foreign interest rates for a loan in period $t-1$ (paid at the beginning of period $t$ ); $T C_{t-1}$ is the transaction cost for foreign borrowing or lending in period $t-1 ; P F_{t}(l)$ and $R E_{t}(l)$ are the household's shares of total profits and rents; $T R_{t}(l)$ are government transfers (discussed below); and $A C_{W, t}(l)$ is the household's cost of adjusting wages. Wage adjustment costs (as a proportion of wage income) are assumed to be given by the following quadratic function:

$$
A C_{W, t}(l)=\frac{\omega_{W}}{2}\left(\frac{W_{t}(l)}{W_{t-1}(l)}-1\right)^{2} .
$$

Each household chooses consumption and sets the wage rate to maximize lifetime utility (17) subject to the budget constraint (19) and labor demand (15). The household optimization yields the following first-order conditions:

$$
\begin{aligned}
& \frac{\beta C_{t}(l)^{\rho} P_{t}}{C_{t+1}(l)^{\rho} P_{t+1}}=\frac{1}{1+R_{t}}, \\
& \frac{S_{t}}{S_{t+1}}=\frac{\left(1+R_{t}^{*}\right)\left(1-T C_{t}\right)}{1+R_{t}}, \\
& \left(\varepsilon_{L}-1\right)\left(1-A C_{w, t}(l)\right) W_{t}(l)=\varepsilon_{L} \psi L_{t}^{\mu} P_{t} / C_{t}^{-\rho}-W_{t}(l)^{2} \partial A C_{W, t}(l) / \partial W_{t}(l) \\
& -\left[\left(W_{t}(l) W_{t+1}(l) L_{t+1}\right) /\left(\left(1+R_{t}\right) L_{t}\right)\right] \partial A C_{W, t+1}(l) / \partial W_{t}(l) .
\end{aligned}
$$

In steady state with $W_{t}(l)=W_{t-1}(l),(23)$ simplifies to $W_{t}(l) / P_{t}=\left(\varepsilon_{L} /\left(\varepsilon_{L}-1\right)\right) \psi L_{t}^{\mu} / C_{t}^{-\rho}$.

\section{Firms}

Each firm takes demand for its variety as given and sets prices to maximize the present discounted value of profits. Price changes are subject to adjustment costs. Price adjustment costs (as a proportion of profits) for the two goods are of the same form as wage adjustment costs, and are given by the following quadratic functions:

$$
A C_{T, t}(h)=\frac{\omega_{P}}{2}\left(\frac{P_{T H, t}(h)}{P_{T H, t-1}(h)}-1\right)^{2}, T=M, X,
$$

where the adjustment cost parameter, $\omega_{P}$, is assumed to be the same for both sectors. 
Firms in both sectors are able to price discriminate between the home and foreign markets. For simplicity, we assume that prices in both markets are set in terms of the home currency. Let $P_{T H, t}^{\prime}(h)$ denote the home-currency price of a home variety of good $T$ set for the foreign market. This price is related to the foreign-currency price of the variety abroad as

$$
P_{T H, t}^{\prime}(h)=S_{t} P_{T H, t}^{*}(h) /\left(1+\tau_{T}^{*}\right), \quad T=M, X,
$$

where $\tau_{T}^{*}$ represents the foreign import tariff rate. Define $P_{T H, t}^{\prime}=\left[\int_{0}^{1} P_{T H, t}^{\prime}(h)^{1-\varepsilon_{T}} d h\right]^{1 /\left(1-\varepsilon_{T}\right)}$, $P_{T H, t}^{*}=\left[\int_{0}^{1} P_{T H, t}^{*}(h)^{1-\varepsilon_{T}} d h\right]^{1 /\left(1-\varepsilon_{T}\right)}$, and use (25) to obtain $P_{T H, t}^{\prime}(h) / P_{T H, t}^{\prime}=P_{T H, t}^{*}(h) / P_{T H, t}^{*}$. Using this condition, (6) and (10), we can express profits of a home firm in each sector as

$$
\begin{aligned}
& P F_{T, t}(h)=\left(P_{T H, t}(h)-M C_{T, t}\right) C_{T H, t}\left(P_{T H, t}(h) / P_{T H, t}\right)^{-\varepsilon_{T}}\left(1-A C_{T, t}(h)\right) \\
& +\left(P_{T H, t}^{\prime}(h)-M C_{T H, t}\right) C_{T H, t}^{*}\left(P_{T H, t}^{\prime}(h) / P_{T H, t}^{\prime}\right)^{-\varepsilon_{T}}\left(1-A C_{T, t}^{\prime}(h)\right), T=M, X,
\end{aligned}
$$

where $A C_{T, t}^{\prime}(h)$ is the adjustment cost for the foreign-market price analogous to (24). The firm chooses $P_{T H, t}(h)$ and $P_{T H, t}^{\prime}(h)$ to maximize $\sum_{s=t}^{\infty} D_{t, s} P F_{T, s}(h)$, where $D_{t, s}$ denotes the rate used to discount $s$-period values at period $t$. The optimal choice for $P_{T H, t}(h)$ satisfies the following first-order condition, for $T=X, M$ :

$$
\begin{aligned}
& \left(1-A C_{T, t}(h)\right)\left(\varepsilon_{T}-1\right) P_{T, t}(h)=\left(1-A C_{T, t}(h)\right) \varepsilon_{T} M C_{T, t} \\
& -P_{T H, t}(h)\left(P_{T H, t}(h)-M C_{T, t}\right) \partial A C_{T, t}(h) / \partial P_{T H, t}(h) \\
& \left.-\left[P_{T H, t}(h)\left(P_{T H, t+1}(h)-M C_{T, t+1}\right) C_{T H, t+1}\right) /\left(\left(1+R_{t}\right) C_{T H, t}\right)\right] \partial A C_{T H, t+1}(h) / \partial P_{T H, t}(h) .
\end{aligned}
$$

In steady state, (27) reduces to $P_{T, t}(h)=\left(\varepsilon_{T} /\left(\varepsilon_{T}-1\right)\right) M C_{T, t}$. The first-order conditions for $P_{T H, t}^{\prime}$ has the same form as (27) and implies that $P_{T H, t}^{\prime}(h)=P_{T H, t}(h)$. It follows that

$$
P_{T H, t}=S_{t} P_{T H, t}^{*} /\left(1+\tau_{T}^{*}\right), \quad T=M, X .
$$

Assuming similar price setting by foreign firms, we also have

$$
P_{T F, t}=\left(1+\tau_{T}\right) S_{t} P_{T F, t}^{*}, \quad T=M, X,
$$

where $\tau_{T}$ is the home import tariff rate. 


\section{E. Equilibrium}

In equilibrium, all households make the same choice. Thus, aggregating over all households, $C_{t}=C_{t}(l), L_{t}=L_{t}(l), W_{t}=W_{t}(l)$. Also, since all households receive the same share of rents, profits, and transfers, $R E_{t}=R E_{t}(l), P F_{t}=P F_{t}(l), T R_{t}=T R_{t}(l)$. Output of each sector equals demand at home and abroad, so that

$$
Y_{T, t}=C_{T H, t}+C_{T H, t}^{*}, \quad T=M, X .
$$

Foreign demand, $C_{T H, t}^{*}$, is determined by (10). The small home economy is assumed to have negligible effect on foreign prices, $P_{T, t}^{*}$. Total labor supply equals the sum of labor demand in the two sectors:

$$
L_{t}=L_{M, t}+L_{X, t}
$$

For each sector, there is a fixed supply of capital specific to the sector. Letting a bar over the variable denote fixed supply, we have

$$
K_{T, t}=\bar{K}_{T, t}, \quad T=M, X
$$

Tariff revenue is redistributed to households in the form of lump-sum transfers. Thus total household transfers is

$$
T R_{t}=\tau_{M} S_{t} P_{M F, t}^{*} C_{M F, t}+\tau_{X} S_{t} P_{X F, t}^{*} C_{X F, t}
$$

National product at home prices equals

$$
N P_{t}=P_{M H, t} Y_{M, t}+P_{X H, t} Y_{X, t}+T R_{t}=W_{t} L_{t}\left(1-A C_{W, t}\right)+R E_{t}+P F_{t}+T R_{t}
$$

Aggregating household budget constraints, noting that home bonds are not held abroad

$\left(\int_{0}^{1} B_{t}(l) d l=0\right)$, and using (34), we can express the national budget constraint as

$$
S_{t} B_{t+1}^{*}=S_{t}\left(1+R_{t-1}^{*}\right)\left(1-T C_{t-1}\right) B_{t}^{*}+N P_{t}-P_{t} C_{t}
$$

Following Laxton and Pesenti (2003), we assume that transaction costs are the following function of the real value of net foreign assets

$$
T C_{t}=\phi_{1} \frac{\exp \left(\phi_{2} S_{t} B_{t+1}^{*} / P_{t}\right)-1}{\exp \left(\phi_{2} S_{t} B_{t+1}^{*} / P_{t}+1\right.}, \quad \phi_{1}>0, \phi_{2}>0
$$

According to this function, $T C_{t}=0$ when $B_{t+1}^{*}=0$. The current account is determined as 


$$
C A_{t}=S_{t}\left(B_{t+1}^{*}-B_{t}^{*}\right)
$$

We consider a range of monetary policies. The polar cases of pure fixed and flexible exchange rates have received considerable attention in the literature. These special regimes can be represented by the following assumptions

$$
\begin{aligned}
& S_{t}=\bar{S}, \\
& P_{t}=\bar{P},
\end{aligned}
$$

where the pure flexible exchange rate case is identified with a policy of fixing the price level (or maintaining a zero rate of inflation). ${ }^{7}$ We also explore a monetary policy regime that uses the interest rate as an instrument and targets the price level. This policy regime is described by the following interest rate rule:

$$
R_{t}=\bar{R}+\delta \log \left(P_{t} / \bar{P}\right), \quad \delta>0,
$$

where $\bar{R}$ denotes the steady-state value of the interest rate and $\bar{P}$ is the price-level target. This rule represents a flexible price-level targeting policy. A stronger interest rate response (a larger value of $\delta$ ) would keep the price level closer to the target. Indeed, the monetary policy rule (39) that fixes the price level (and lets the exchange rate float) can be obtained from (40) in the limit by letting $\delta \rightarrow \infty$.

Under the assumption that the home price level is stationary, (21) implies that $\bar{R}=(1-\beta) / \beta$. Assuming that the home and foreign discount factors are the same $\left(\beta=\beta^{*}\right)$ and the foreign price level is also stationary, the value of net foreign assets equals zero in the steady state according to the foreign counterpart of (21), (22), and (36). Our model, however, allows the home country to accumulate net foreign wealth or debt in the transition process. In our quantitative analysis below, we also consider the case of a financially closed economy with no international borrowing or lending. This case can be represented by the assumption that households cannot hold foreign bonds (needed for international capital transactions). Letting $B_{t}^{*}(l)=B_{t+1}^{*}(l)=0$ in the household budget constraint (19), and aggregating over all households, the national budget constraint (35) is modified to $N P_{t}=P_{t} C_{t}$, for the no-international-capital-mobility case. Relation (22), moreover, no longer holds in this case. Even in the absence of international capital mobility, the country can follow macroeconomic policy alternatives given by (38)-(40). Note that the fixed exchange rate policy (38) does not require the use of international reserves and could be implemented by interest rate control.

\footnotetext{
${ }^{7}$ The model could be easily extended to allow for a deterministic inflation rate. In this case, nominal variables can be redefined as deviations from a deterministic trend.
} 


\section{Quantitative Analysis}

\section{A. Calibration}

We calibrate the model for a small developing economy that has higher tariffs initially than the large foreign economy. Parameterization of the baseline model is summarized in Table 1. Assume that home tariffs equal 20 percent while foreign tariffs equal 10 percent (i.e., $\left.\tau_{M}=\tau_{X}=.2, \tau_{M}^{*}=\tau_{X}^{*}=.1\right){ }^{8}$ We choose the following values for various shares in the initial steady state before trade liberalization (a bar over a variable denotes its initial steady-state value). Both goods are assumed to have equal share in aggregate consumption, so that $\bar{P}_{X} \bar{C}_{X}=\bar{P}_{M} \bar{C}_{M}=.5 \bar{P} \bar{C}$. We also assume that imports (equal to exports in steady state) account for a quarter of aggregate expenditures, i.e., $\bar{P}_{M F} \bar{C}_{M F}+\bar{P}_{X F} \bar{C}_{X F}=\bar{S}\left(\bar{P}_{M H}^{*} \bar{C}_{M H}^{*}+\bar{P}_{X H}^{*} \bar{C}_{X H}^{*}\right)=.25 \bar{P} \bar{C}$. This value accords with average long-run shares of imports and exports in GDP for all developing countries. ${ }^{9}$ Given product differentiation, there is intraindustry trade for both goods, but we assume that there is interindustry trade as well and the home country is a net importer (exporter) of good $M(X)$. Imports of $M$ are assumed to be 80 percent of total imports while exports of $X$ are assumed to be a similar percentage of total exports. ${ }^{10}$ The labor share, $\bar{W} \bar{L} / \bar{P} \bar{C}$, is set equal to 0.6 .

We normalize the initial steady state values of consumption and the wage rate $(\bar{C}, \bar{W})$ to equal one. We also set the initial values of all price indexes at home ( $\bar{P}, \bar{P}_{M}, \bar{P}_{X}, \bar{P}_{M H}, \bar{P}_{M F}, \bar{P}_{X H}, \bar{P}_{X F}$ ) equal to one by normalization. Given our assumed shares, these normalizations imply that $\chi_{M}=\chi_{X}=0.5, \chi_{M F}=0.4, \chi_{M H}=0.6, \chi_{X F}=0.1$, and $\chi_{X H}=0.9$. We assume that the size of the foreign economy is very large in relation to the home economy, and thus home tariff cuts have a negligible effect on the foreign price indexes of the two goods $\left(P_{M, t}^{*}\right.$ and $\left.P_{X, t}^{*}\right)$ and the foreign interest rate $\left(R_{t}^{*}\right)$. These variables are treated as exogenous and assumed to be constant. ${ }^{11}$ Foreign price indexes, $\bar{P}_{M}^{*}, \bar{P}_{X}^{*}, \bar{P}_{M F}^{*}, \bar{P}_{X F}^{*}$, are also normalized to equal one. We use (29) to determine the value of $\bar{S}$.

\footnotetext{
${ }^{8}$ Tariff rates tend to be higher for developing countries than for industrial countries. According to recent estimates by Anderson and Martin (2006), the average (import-weighted) tariff rates for developing and industrial countries were 10 percent and 3 percent, respectively. We assume the higher rate to allow for additional restrictions arising from non-tariff barriers.

${ }^{9}$ The average share of imports in GDP for all developing countries over the 1990-2004 period is 26.1 percent and that of exports is 25.9 percent (source: WEO database).

${ }^{10}$ These assumptions imply that intraindustry trade accounts for about 40 percent of total trade for each good.

${ }^{11}$ In view of the foreign counterpart of (8), this assumption implies that the values of $\chi_{M H}^{*}$ and $\chi_{X H}^{*}$ are very small. Note that for our normalizations and assumptions regarding $\bar{C}_{M H}^{*}$ and $\bar{C}_{M H}^{*}$, the values of $\chi_{M H}^{*} \bar{C}_{M}^{*}$ and $\chi_{X H}^{*} \bar{C}_{X}^{*}$ are determined by (10), (28), and (29). However, values of $\chi_{M H}^{*}$ and $\chi_{X H}^{*}$ can still be made arbitrarily close to zero by choosing sufficiently large values of $\bar{C}_{M}^{*}$ and $\bar{C}_{X}^{*}$.
} 
Letting one-quarter represent a unit of time in the model, the discount factor $(\beta)$ is assumed to be 0.99 , which implies an estimate of the annualized real rate of interest equal to 4 percent. There is a wide range of estimates for other parameters of the utility function. For the baseline version, we choose a value of 0.5 for the intertemporal elasticity of substitution $(1 / \rho)$, and 0.25 for the elasticity of labor supply $(1 / \mu)$. Alternative values of these parameters are explored in our sensitivity analysis. Given the choice of values for $\rho, \mu, \bar{C}, \bar{L}$, and of $\varepsilon_{L}$ (as discussed below), the steady-state version of (23) is used to determine the value of $\psi$ (the weight for the labor effort index in the utility function).

The substitution elasticity between the two traded goods $(\eta)$ is set equal to 3.0. We choose a value of 6.0 for the elasticity of substitution between home and foreign bundles of each good $\left(\theta_{M}, \theta_{X}\right)$, which is broadly consistent with recent estimates by Hertel and others. (2004). ${ }^{12}$ Substitution elasticities for varieties of each product category $\left(\varepsilon_{M}, \varepsilon_{X}\right)$ are assumed to equal 8.0. This value implies a mark-up of a little less than 15 percent and is within the range of various estimates for markups. ${ }^{13}$ As the elasticity of substitution between home and foreign varieties and the markup (reflecting the degree of imperfect competition) could potentially play an important role in determining the effects of trade liberalization, we also consider variations of the baseline model that allow different values for these parameters. Although the home country is small, it still has monopoly power (because of producing differentiated goods) that depends on the elasticities of substitution between home and foreign varieties in the foreign market $\left(\theta_{M}^{*}, \theta_{X}^{*}\right)$. We let these elasticities equal 12.0. This value leads to a reasonable value for Nash optimal tariff of less than 10 percent.

The substitution elasticity for labor services $\left(\varepsilon_{L}\right)$ is assumed initially to also equal 8.0, which makes the markup in the labor market the same as that in the goods market. Later, we explore the sensitivity of results to different values of this elasticity. The elasticity of substitution between labor and capital $(\sigma)$ is generally considered to be close to one, and we assume that this value equals $0.9 .{ }^{14}$ We introduce labor intensity differences between the two goods and assume that good $X$ (the net export of the home country) is labor intensive $\left(\alpha_{X}>\alpha_{M}\right){ }^{15}$

\footnotetext{
${ }^{12}$ Their estimates of the elasticity vary across sectors and average to a value close to 6.0.

${ }^{13}$ Martins, Scarpetta, and Pilat (1996), for example, estimate the average markup for manufacturing sectors in OECD countries at around 20 percent. Chari, Kehoe, and McGrattan (2002) use a markup estimate of 11 percent based on studies of the United States.

${ }^{14}$ For the use of a similar value, see Jomini and others (1991), for example.

${ }^{15}$ We let $\alpha_{M}=1.25 \alpha_{X}$ and determine $\alpha_{M}$ and $\alpha_{X}$ to make $\bar{L}_{M}$ and $\bar{L}_{X}$ consistent with the assumption that $\bar{L}=.6$.
} 
Parameters of the adjustment cost functions $\left(\omega_{P}\right.$ and $\left.\omega_{W}\right)$ determine the degree of wage-price inertia. There are no reliable estimates for these parameters. We use a value of 800 for each parameter in the baseline case, which is within the range of recent estimates. ${ }^{16}$ Alternative values of the parameters are considered in our sensitivity analysis. In the transaction cost function, values of both parameters $\left(\phi_{1}\right.$ and $\left.\phi_{2}\right)$ are assumed to equal 0.01 . This assumption implies a very slow convergence to a steady state with zero net foreign assets. Variations in this assumption make little difference to the results.

\section{B. Macroeconomic Adjustment}

We first discuss the macroeconomic effects of trade liberalization under pure fixed and flexible exchange rate regimes. Trade liberalization takes the form of a unilateral reduction of home tariffs from 20 to 10 percent. ${ }^{17}$ The DYNARE program is used to obtain a deterministic steady-state solution to the nonlinear model before and after trade liberalization and to derive the dynamic response of model variables to this policy.

Figure 1 shows the dynamic response of output, employment, consumption, and the current account over 20 quarters to a decrease in home tariff rates by 10 percentage points in the baseline model under the two polar exchange rate regime. ${ }^{18}$ The macroeconomic dynamics in this model arise from stickiness in wages and prices. To illustrate the influence of these nominal rigidities, the figure also displays time paths of the variables in a variant of the model where these rigidities are absent and wages and prices are fully flexible (these time paths are derived by setting $\omega_{P}=\omega_{W}=0$ in the baseline model). In this variant, there is no transitional dynamics and the tariff cut causes all variables to adjust to their new steady-state values in the same period. As the figure shows, the response of variables in the presence of nominal rigidities for both exchange rate regimes is very different than that under no nominal rigidities.

In the case of sticky wages and prices and fixed exchange rates, the tariff cut lowers the price of foreign varieties relative to home varieties and shifts demand from domestic to imported goods. This shift leads to an initial decline in both output and employment. The output and employment response in this case is opposite to that in the model without any nominal rigidity. Also, consumption decreases less than output because of consumption smoothing considerations, and thus, the tariff reduction causes a temporary deterioration in the current account.

\footnotetext{
${ }^{16}$ Bayoumi, Laxton, and Pesenti (2004), for example, use values of 1400 and 700 for the euro area and the rest of the world, respectively, for the parameters of a variant of the adjustment cost functions used in this paper.

${ }^{17}$ Both $\tau_{M}$ and $\tau_{X}$ are reduced from 0.2 to 0.1 , while $\tau_{M}^{*}$ and $\tau_{X}^{*}$ are kept equal to 0.1 .

${ }^{18}$ Output is defined as $\left(P_{M H, t} Y_{M, t}+P_{X H, t} Y_{X, t}\right) / P_{t}$. Quarter 1 represents the initial steady state and quarter two the first quarter after tariff reduction.
} 
In contrast, home-currency depreciation under flexible exchange rates brings about an initial increase in output and employment by stimulating foreign demand for domestic goods and dampening the shift in home demand from domestic to imported goods. In fact, the exchange rate overshoots its new equilibrium value and the initial expansion in output and employment is greater than that in the absence of nominal rigidities. As consumption increases less than output, flexible exchange rates lead to a current account surplus.

Figure 2 illustrates how the response of key nominal variables to lower tariffs differs between the two regimes. Under fixed exchange rates, the interest rate does not change and the price level falls gradually to accommodate the relative price changes induced by tariff cuts. In the case of flexible exchange rates, on the other hand, the price level is not allowed to adjust and the exchange rate initially jumps above its long-run value. ${ }^{19}$ This response requires a sharp initial reduction in the interest rate. ${ }^{20}$

\section{Welfare Effects}

We next examine welfare effects of trade liberalization under different monetary policies. Welfare gains are measured by an equivalent-variation index, $\gamma$, which is defined as the constant amount (expressed as a fraction of steady-state consumption before trade liberalization) that needs to be given to households to make them indifferent between the initial steady state and the new state (including the transition period) after trade liberalization. This index is given by the following relation:

$$
\sum_{s=0}^{\infty} \beta^{s} u[(1+\gamma) \bar{C}, \bar{L}]=\sum_{s=t_{0}}^{\infty} \beta^{s-t_{0}} u\left(C_{s}, L_{s}\right)
$$

where $\left\{C_{s}, L_{s}\right\}_{s=t_{0}}^{\infty}$ is the sequence of consumption and labor supply after trade liberalization at time $t_{0}$, and $u($.$) is defined in (18). The index \gamma$ measures the total welfare effect of tariff reduction and can be decomposed as

$$
\gamma=\gamma_{T R}+\gamma_{S S}
$$

where $\gamma_{T R}$ and $\gamma_{S S}$ measure the transitional and steady-state welfare effects of trade liberalization. Letting a tilde denote a variable's steady-state value after trade liberalization, we calculate the steady-state index as

\footnotetext{
19 The reason for the overshooting behavior of the exchange rate in response to tariff reduction is similar to that for the well-known Dornbusch (1976) result that under sticky prices, a permanent increase in the money supply causes the exchange rate to overshoot its equilibrium value.

${ }^{20}$ The interest rate in fact falls to a level very close to zero. Note that a flexible exchange rate regime with a fixed price level would not be feasible if the adjustment requires the interest rate to fall below zero.
} 


$$
u\left[\left(1+\gamma_{S S}\right) \bar{C}, \bar{L}\right]=u(\tilde{C}, \tilde{L}),
$$

and use (42) to determine the transitional index residually. Note that if wages and prices were fully flexible, the transitional effect would disappear (consumption and employment would change from $\bar{C}$ and $\bar{L}$ to $\tilde{C}$ and $\tilde{L}$ at $t_{0}$ ) and $\gamma$ would equal $\gamma_{S S} .{ }^{21}$

Table 2 displays the welfare effects of trade liberalization for the baseline model as well as two variations of this model. In this table, the welfare indexes are multiplied by 100 to express these in percentage terms. For the baseline model, the table shows that lowering tariff rates by 10 percentage points leads to a steady-state welfare gain of about 0.4 percent of initial steady-state consumption. The transition process involves a loss which is larger under fixed than flexible exchange rates. However, even in the fixed exchange rate case, the loss is small and amounts to about 12.5 percent of the steady-state gain. Thus our results suggest that accounting for macroeconomic adjustment makes only a small difference to the estimate of the welfare effect of trade liberalization.

The table also explores the sensitivity of the results to variations in the assumptions about the degree of competition in the goods markets. Trade models often assume traded goods to be more competitive than the baseline model. Variation 1 moves in this direction by raising the elasticity of substitution between home and foreign goods and lowering the markup for both goods. In this variation, $\theta_{M}=\theta_{X}=9$ and $\varepsilon_{M}=\varepsilon_{X}=11$. As would be expected, a greater degree of competitiveness leads to higher steady-state gains. Interestingly, more competition in traded goods decreases the transitional loss for flexible exchange rates, but increases it for fixed exchange rates. Variation 2 explores an asymmetric case where good $\mathrm{M}$ is less competitive while good $\mathrm{X}$ is more competitive than the baseline model. For this case, we let $\theta_{M}=4, \theta_{X}=9, \varepsilon_{M}=6$, and $\varepsilon_{X}=11$. The asymmetric case does not make much difference and produces only small changes in both the steady-state and transitional effects.

We next explore the welfare effects of macroeconomic adjustment under the interestrate rule spelled out in equation (40). Under this rule, the parameter $\delta$ represents the monetary policy response to deviations from the price-level target. Although different values of $\delta$ do not affect the new steady-state levels of variables, they influence the macroeconomic adjustment and thus can alter the transitional loss associated with tariff reduction. An interesting issue is whether a weaker interest rate response to the price level would improve or worsen welfare. Figure 3 shows the relation between the transitional loss $\left(100 \gamma_{T R}\right)$ and $\delta$. As the figure shows, the transitional loss falls as $\delta$ decreases and becomes very small as $\delta$ gets close to zero.

\footnotetext{
${ }^{21}$ Note, however, that the equilibrium in the flexible wage-price case does not represent the socially optimal allocation because of the presence of distortions in the model.
} 
The reason why the transitional loss increases with $\delta$ can be explained with the help of Figure 1. For a very large value of $\delta$, the macroeconomic response of real variables is very close to the response under pure flexible exchange rates shown in the figure. As $\delta$ decreases, the path of the variables moves towards the no-nominal-rigidities path in the figure. For very small values of $\delta$, the interest rate rule gets close to duplicating the flexible wage-price equilibrium, and nearly eliminates the transitional loss.

Although a weak monetary policy response to the price level helps reduce transitional losses caused $b$ y tariff cuts, two caveats need to be added. First, in a more general model, the optimal response would also depend on shocks other than trade policy changes. Second, our analysis assumes that monetary policy can commit itself to any form of the rule. If this is not the case, a weak response to the price level may not be desirable because it could signal a lack of commitment to the price-level target.

\section{Sensitivity Analysis}

We performed extensive sensitivity analysis to examine the robustness of our results to alternative values of the key parameters. We first explored the effects of alternative values for the parameters $\rho, \mu$, and $\varepsilon_{L}$, which could potentially influence both short- and long-run effects of the tariff reduction. We let $\rho$ and $\mu$ vary from 2 to 5 , and $\varepsilon_{L}$ from 6 to 11 . These variations exert little effect on the steady-state welfare measure. The transitional loss also does not change much for most variations. Under fixed exchange rates, the transitional loss remains within 10 to 15 percent of the steady-state gain. The transitional loss is generally smaller under flexible exchange rates, but varies over a wider range. These differences are illustrated in Figure 4. For variations considered in our sensitivity analysis, the figure shows the frequency distribution of estimates for the ratio of the transitional loss to the steady-state gain under the two regimes. The distribution of the loss-ratio estimates for flexible exchange rates is centered around a lower value but is more widely dispersed than fixed exchange rates. We also examined the results for flexible price-level targeting, but did not find these to be very sensitive to parameter variations. For all variations, a decrease in $\delta$ under flexible price-level targeting reduces the transitional loss, and this loss is virtually eliminated for very small values of $\delta$.

We also explored how the results are affected by the degree of wage-price stickiness. First, we let the adjustment cost parameters for wages and prices $\left(\omega_{W}, \omega_{P}\right)$ vary together over a wide range of values from 200 to 1400 . Greater wage-price inertia would be expected to increase the cost of macroeconomic adjustment as it would cause slower adjustment to tariff cuts. Indeed, as shown in Figure 5, we find that higher values of adjustment cost parameters lead to larger transitional losses. Figure 5 also shows that flexible exchange rates generate a smaller transitional loss than fixed exchange rates. The loss difference between the two 
regimes, however, decreases as $\omega_{W}$ and $\omega_{P}$ increase. ${ }^{22} \mathrm{We}$ also experimented with variations that allow prices to be more or less sticky than wages. ${ }^{23}$ These variations did not make much difference to the results.

\section{E. No International Capital Mobility}

Finally, we examine the effect of trade liberalization in the absence of international capital mobility. The steady-state effect without capital mobility is the same as that with capital mobility, since the value of net foreign assets equals zero in the steady state for both cases. Capital mobility, however, plays an important role in the determination of the transitional effect. Consider, first, a policy of fixed exchange rates. ${ }^{24}$ To simplify the analysis of this policy, assume that international reserves are not available and the interest rate is used as an instrument to keep the current account balance equal to zero in each period..$^{25}$ The requirement of maintaining zero current account balance in each period significantly alters the behavior of consumption. As discussed above (and illustrated in Figure 1), there is a significant initial decline in output in response to tariff cuts under fixed exchange rates. Without international borrowing, consumption must match the output response and fall sharply in the initial period. This effect on consumption significantly raises the cost of macroeconomic adjustment to tariff cuts. Indeed, we find that in the baseline model without capital mobility, the transitional loss under fixed exchange rates is considerable and offsets much of the steady-state gain from trade liberalization. ${ }^{26}$

Even with no capital mobility, alternative monetary policies can prevent large transitional losses. A pure flexible exchange rate policy (with a fixed price level) is not feasible in this case as it would require a sharp increase in consumption to match output response, which can not be brought about by a nonnegative interest rate. ${ }^{27}$ However, a

\footnotetext{
${ }^{22}$ The difference between the two regimes, in fact, would eventually reverse if higher values of $\omega_{W}$ and $\omega_{P}$ were considered. One reason for this behavior is that greater wage-price stickiness exacerbates the overshooting behavior of the exchange rate and thus leads to a more rapid increase in the transitional loss under flexible exchange rates.

${ }^{23}$ In these variations, we kept the value of one of the parameters $\left(\omega_{W}\right.$ or $\left.\omega_{P}\right)$ constant at the baseline level of 800 and varied the value of the other parameter from 200 to 1800 .

${ }^{24}$ Husain, Mody, and Rogoff (2004) find that fixed exchange rates often perform well and are a durable regime for financially closed economies.

${ }^{25}$ Financially closed countries tend to have low income levels and it is reasonable to assume that these economies generally lack adequate international reserves.

${ }^{26}$ In this case, a tariff cut by 10 percentage points causes a transitional loss equal to 0.26855 percent of GDP. This amount is around 70 percent of the steady-state gain shown in Table 2.

${ }^{27}$ Our simulation shows that the (annualized) real interest rate needs to fall in the initial period by a large amount (by about 80 percentage points) if the price level is not allowed to change. Note that even in an extended model that allows for deterministic inflation rate, this policy would require a very high inflation rate to keep the nominal interest rate positive.
} 
flexible exchange rate policy that allows the price level to fall could be implemented and would save transitional losses associated with fixed exchange rates. For example, an interest rate rule with $\delta=0.75$ would keep the interest rate above zero and transitional losses under this policy would be close to zero.

\section{Conclusions}

Trade liberalization offers long-run efficiency benefits, but it can also give rise to costly short-run macroeconomic adjustment. Although there is an extensive literature on measuring the long-term gains from trade liberalization, there is little or no work on estimating the short-term costs of this policy. This paper provides estimates of these costs based on a framework that incorporates key features of international trade models and macroeconomic models. The estimates are derived for a small developing economy that initially has higher trade restrictions in the form of tariffs than the rest of the world.

The paper focuses on the case of an economy that is well integrated into global financial markets. For such an economy, the short-run costs of tariff reduction are found to be higher under fixed than flexible exchange rates for plausible parameter values. Under both exchange rate regimes, moreover, the short-run loss caused by tariff cuts is small relative to the long-run gain from this policy. Under a fixed exchange rate, for example, the ratio of the short-run loss to the long-run gain is between 10 and 15 percent for a wide range of parameter values. The paper also shows that the adjustment costs of trade liberalization are not only relatively small but also can be avoided by an appropriate monetary policy. Costly adjustment arises from nominal rigidities that impede adjustment of relative prices and cause real variables to temporarily depart from their long-run equilibrium values. A flexible targeting rule facilitates relative-price adjustment by allowing the aggregate price level to deviate from its target value, and thus helps reduce adjustment costs.

The paper also investigates the role of macroeconomic adjustment for a financially closed economy that can not borrow or lend internationally. For an economy of this type, a fixed exchange rate regime leads to substantial adjustment losses that can dissipate much of the gains expected from trade liberalization. Alternative exchange rate regimes, however, involve small adjustment losses even in the absence of international capital mobility.

The paper's estimates are based on a simple two-sector model. The basic results, however, are likely to hold for extensions of the model to higher dimensions (with more sectors) and variations that introduce nontraded goods and intermediate inputs. Following standard international trade models, the paper's model treats the capital stock as an exogenously determined endowment. Allowing capital to be determined endogenously via investment would represent a significant variation of the model. Exploring how macroeconomic adjustment cost of trade liberalization would be affected by such a variation would be an interesting topic for future research. 


\section{REFERENCES}

Anderson, Kym, and Will Martin, 2006, "Agriculture, Trade Reform, and the Doha Agenda," Agricultural Trade Reform and the Doha Agenda (Washington: World Bank).

Bayoumi, Tamim, Douglas Laxton, and Paolo Pesenti, 2004, "Benefits and Spillovers of Greater Competition in Europe: A Macroeconomic Assessment," NBER Working Paper No. 10416 (Cambridge, Massachusetts: National Bureau of Economic Research).

Boyer, R. S., 1977, "Commercial Policy under Alternative Exchange Rate Regimes," The Canadian Journal of Economics, Vol. 10, No. 2, pp. 218-232.

Chacholiades, Miltiades, 1978, International Monetary Theory and Policy (New York: McGraw Hill).

Chari, V. V., Patrick J. Kehoe, and Ellen R. McGrattan, 2002, "Can Sticky Price Models Generate Volatile and Persistent Real Exchange Rates?" Review of Economic Studies, Vol. 69, No. 3, pp. 533-63.

Dornbusch, Rudiger, 1976, "Expectations and Exchange Rate Dynamics," Journal of Political Economy, Vol. 84, No. 6, pp. 1161-76.

Dornbusch, Rudiger, 1980, Open Economy Macroeconomics (New York: Basic Books).

Hertel, Thomas, David Hummels, Maros Ivanic, and Roman Keeney, 2004, "How Confident Can We Be in CGE-Based Assessments of Free Trade Agreements?" GTAP Working Paper No. 26 (March).

Husain, Aasim, Aska Mody, and Kenneth S. Rogoff, 2004, "Exchange Rate Regime Durability and Performance in Developing Versus Advanced Countries," NBER Working Paper No. 10673 (Cambridge, Massachusetts: National Bureau of Economic Research).

Jomini, Patrick, J.F. Zeitsch, R. McDougall, A. Welsh, S. Brown, J. Hambley, and J. Kelly, 1991, SALTER: A General Equilibrium Model of the World Economy, Vol. 1, Model Structure, Database, and Parameters (Canberra: Productivity Commission).

Krugman, Paul, 1982, "The Macroeconomics of Protection with a Floating Exchange Rate," Carnegie-Rochester Series on Public Policy, 16, pp. 141-82.

Laxton, Douglas, and Paolo Pesenti, 2003, "Monetary Rules for Small, Open, Emerging Economies," Journal of Monetary Economics, Vol. 50, pp. 1109-46.

Martins, J., S. Scarpetta, and D. Pilat, 1996, "Mark-up Pricing, Market Structure and the Business Cycle,” OECD Economic Studies, No. 27, pp. 71-106. 
Mundell, Robert, 1961, "Flexible Exchange Rates and Employment Policy," The Canadian Journal of Economics and Political Science, No. 27 (November), pp. 509-17.

Obstfeld, Maurice, 2004, "Globalization, Macroeconomic Performance and the Exchange Rates of Emerging Economies," NBER Working Paper No. 10849 (Cambridge, Massachusetts: National Bureau of Economic Research).

Razin, A., and L.E.O. Svensson, 1983, "Trade Taxes and the Current Account," Economics Letters, Vol. 13, No. 1, pp. 55-57. 
Table 1. Baseline Model: Parameter Values and Normalizations

Shares

$$
\chi_{M}=\chi_{X}=0.5, \chi_{M F}=0.4, \chi_{M H}=0.6, \chi_{X F}=0.1, \chi_{X H}=0.9
$$

Utility Parameters $\quad \rho=2.0, \mu=4.0, \psi=6.75, \beta=1.0 / 1.01$

Elasticities of Substitution $\quad \eta=3.0, \theta_{M}=\theta_{X}=6.0, \varepsilon_{M}=\varepsilon_{X}=\varepsilon_{L}=8.0$

$\theta_{M}^{*}=\theta_{X}^{*}=12.0$

Technology Parameters $\quad \sigma=.9, \alpha_{M}=.61, \alpha_{X}=.76$

Adjustment and Transaction Costs $\quad \omega_{P}=\omega_{W}=800, \phi_{1}=\phi_{2}=0.01$

Initial Steady-State Values $\quad \tau_{M}=\tau_{X}=.2, \tau_{M}^{*}=\tau_{X}^{*}=.1, \bar{C}=1, \bar{L}=.6, \bar{S}=.833$,

$\bar{W}=\bar{P}=\bar{P}_{M}=\bar{P}_{X}=\bar{P}_{M H}=\bar{P}_{M F}=\bar{P}_{X H}=\bar{P}_{X F}=1$,

$\bar{P}_{M}^{*}=\bar{P}_{X}^{*}=\bar{P}_{M F}^{*}=\bar{P}_{X F}^{*}=1$.

Table 2. Welfare Effects of Trade Liberalization

(in percent of steady-state consumption before trade liberalization)

\begin{tabular}{|c|c|c|c|c|c|}
\hline & \multicolumn{2}{|c|}{ Total Effect (percent) } & \multicolumn{2}{|c|}{ Transitional Effect (percent) } & \multirow{2}{*}{$\begin{array}{l}\text { Steady-State } \\
\text { Effect (percent) }\end{array}$} \\
\hline & Fixed ER & Flexible ER & Fixed ER & Flexible ER & \\
\hline Baseline Model & 0.32972 & 0.34061 & -0.04672 & -0.03583 & 0.37643 \\
\hline Variation 1 & 0.40156 & 0.44428 & -0.05909 & -0.01637 & 0.46065 \\
\hline Variation 2 & 0.30710 & 0.32511 & -0.04137 & -0.02335 & 0.34847 \\
\hline
\end{tabular}

Note: $\theta_{M}=\theta_{X}=9, \varepsilon_{M}=\varepsilon_{X}=11$ for variation 1 , and $\theta_{M}=4, \theta_{X}=9, \varepsilon_{M}=6, \varepsilon_{X}=11$ for varition 2 
Figure 1. Dynamic Response of Real Variables to Trade Liberalization
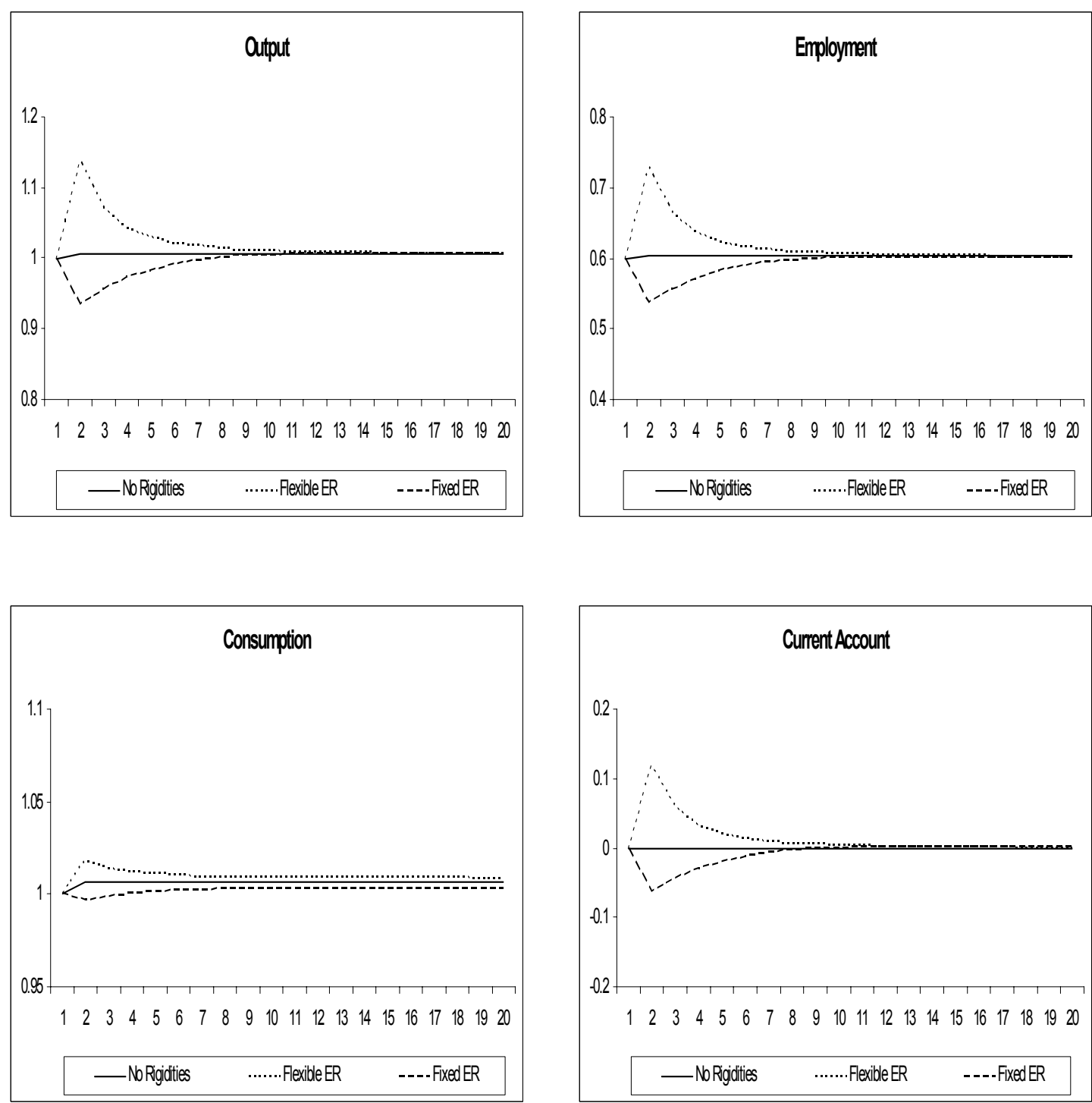
Figure 2. Dynamic Response of Nominal Variables to Trade Liberalization
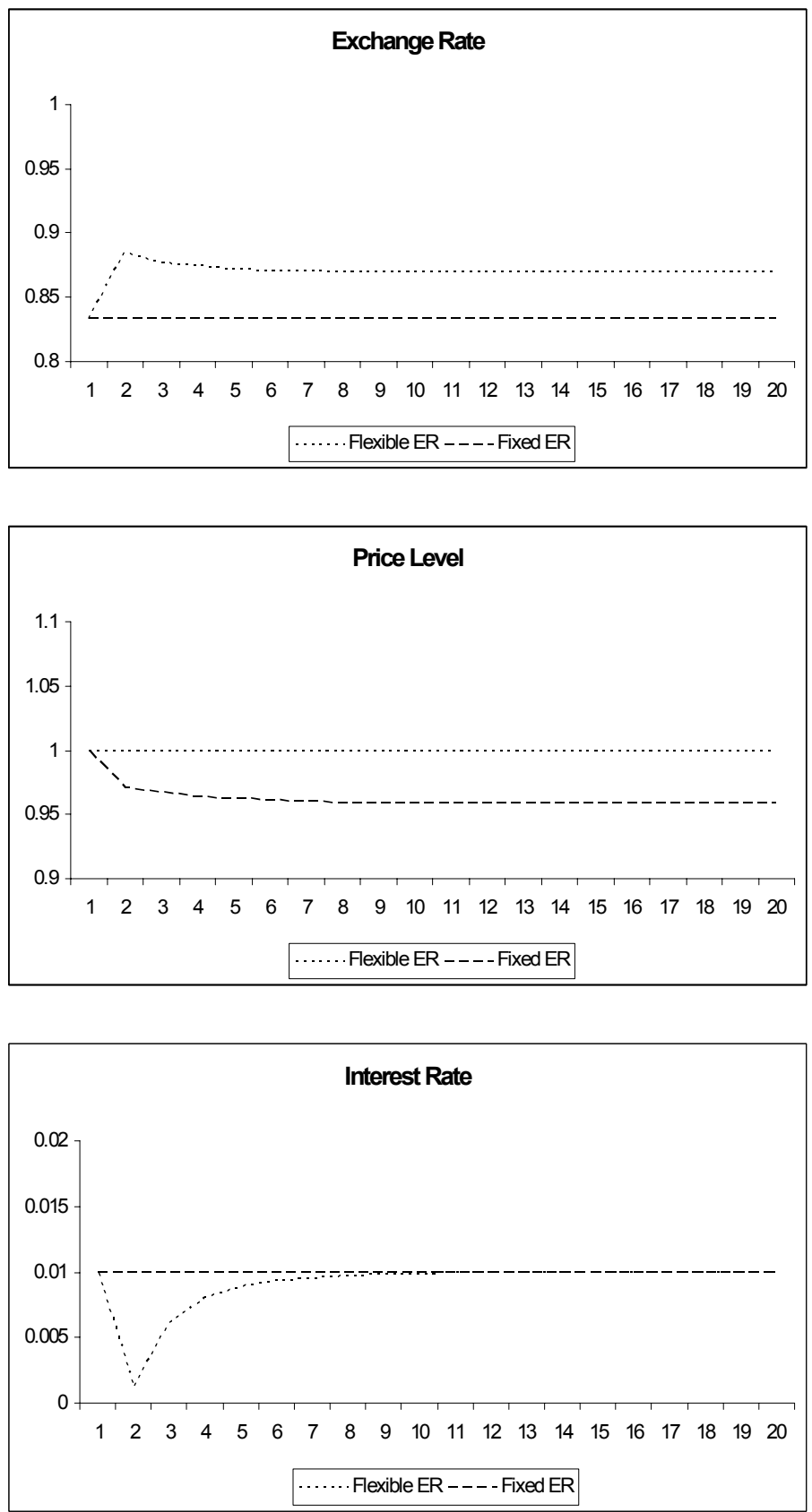
Figure 3. Transitional Losses under Different Values of Delta

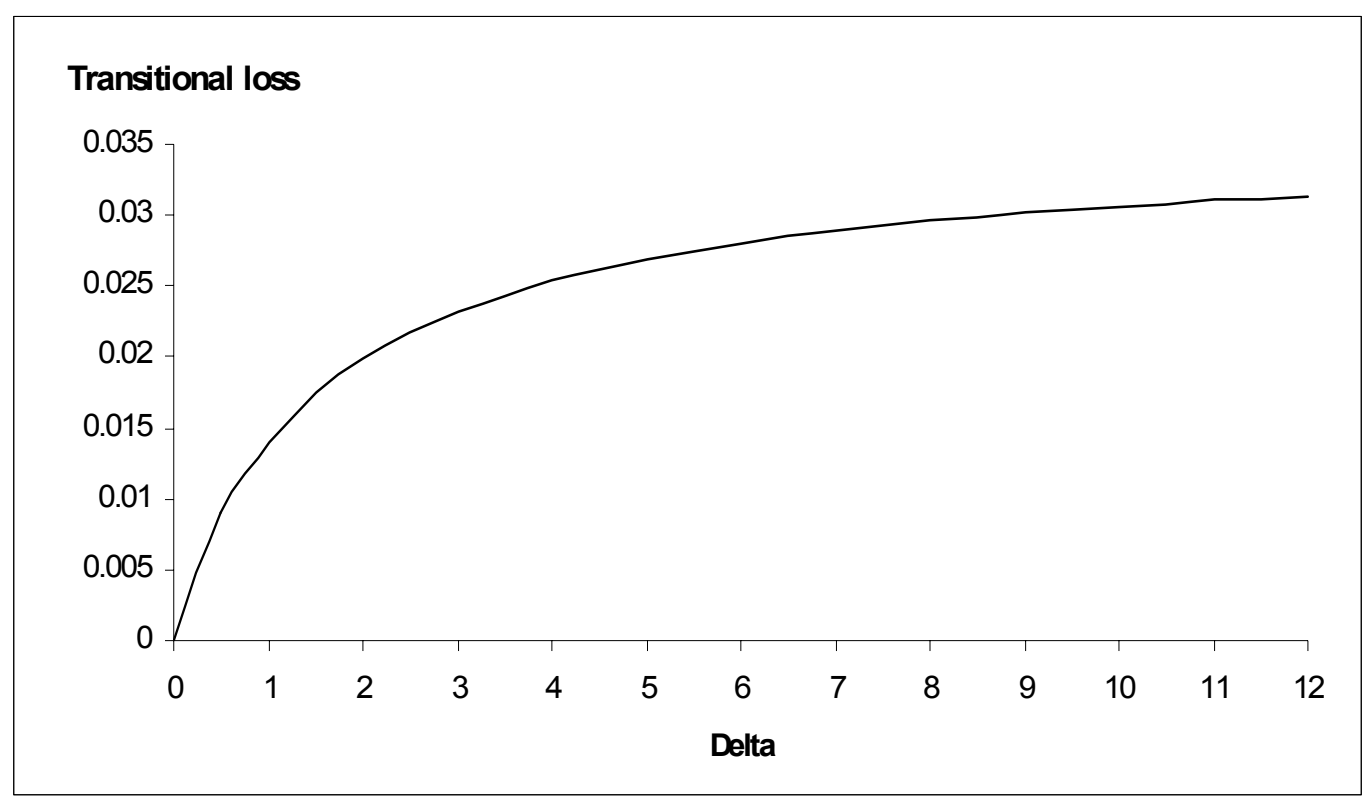

Figure 4. Distribution of Loss-Ratio Estimates under Fixed and Flexible Exchange Rates

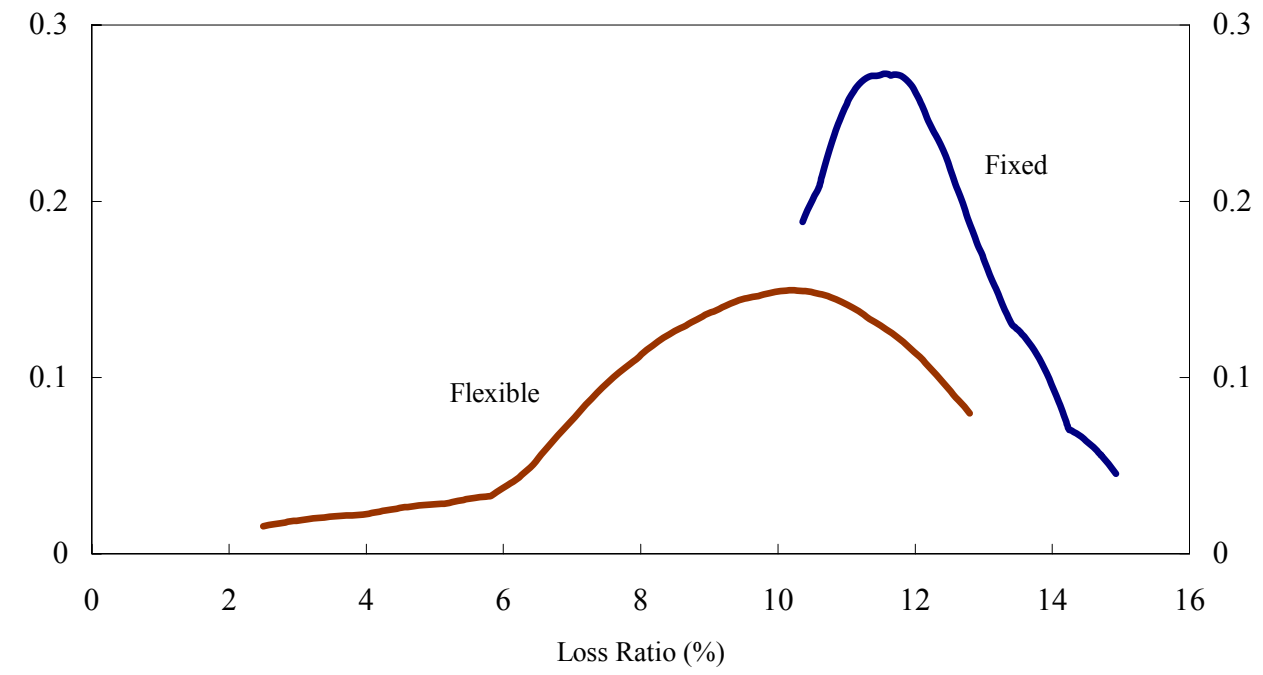

Note: On the horizontal axis, the loss ratio represents the transitional loss as a percentage of steadystate gain; vertical axis measures frequency. Kernel density estimates of the implied distributions (or PDFs) are drawn between minimum and maximum loss-ratio estimates obtained. 
Figure 5. Transitional Losses under Different Values of Omega: Fixed Versus Flexible Exchange Rates

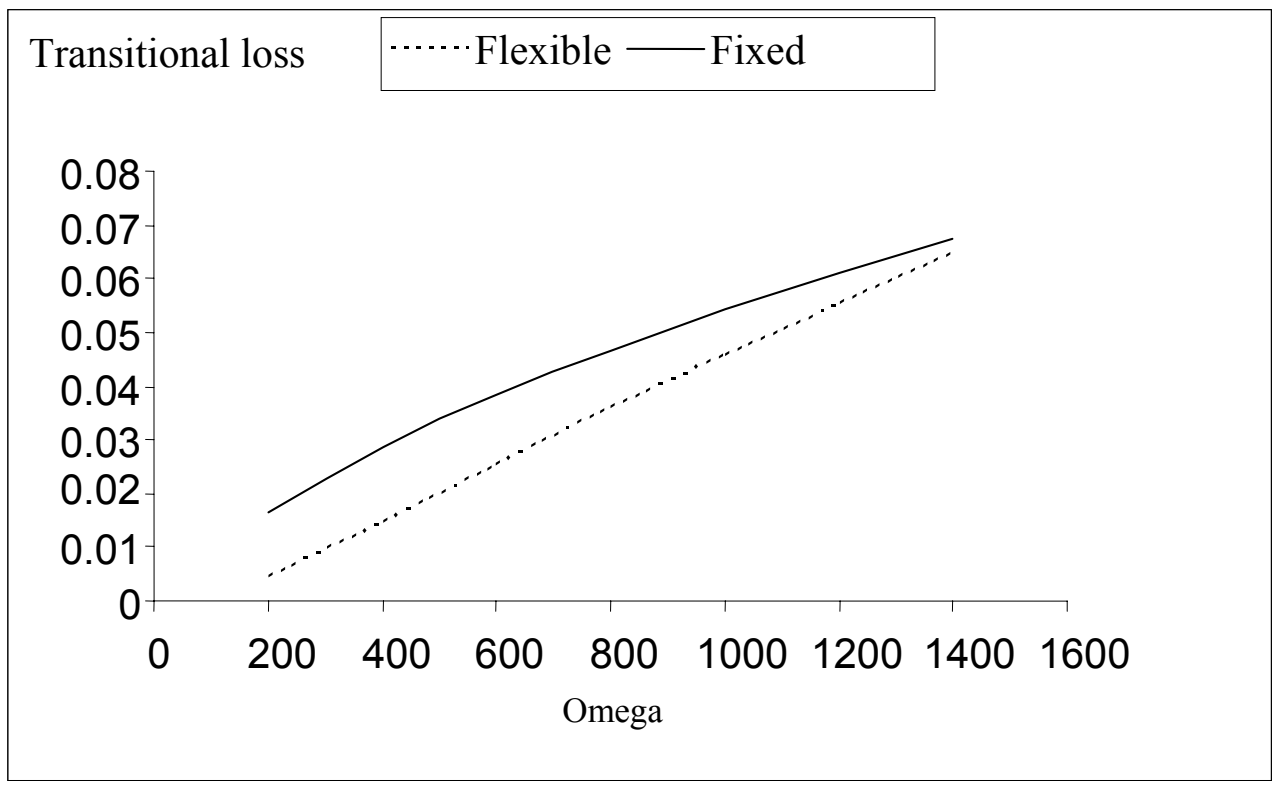

Note: Omega equals both $\omega_{P}$ and $\omega_{W}$. The vertical axis measures the transitional loss as a percentage of the steady-state gain. 